\title{
Mean Platelet Volume Reflect Hematopoietic Potency and Correlated Blood Group $O$ in Cord Blood from Healthy Newborn
}

\author{
Hye Ryun Lee, ${ }^{1}$ Jeong Su Park, ${ }^{2,3}$ Sue Shin, ${ }^{2,3,4}$ Eun Youn Roh,, ${ }^{2,3,4}$ Jong Hyun Yoon,,3,4 \\ Eun Young Song, ${ }^{2}$ Byung Jae Kim, ${ }^{5}$ and Ju Young Chang ${ }^{6}$ \\ ${ }^{1}$ Department of Laboratory Medicine, Gyeongsang National University Hospital, \\ Gyeongsangnam-do, Jinju 660-702, Republic of Korea \\ ${ }^{2}$ Department of Laboratory Medicine, Seoul National University College of Medicine, Seoul 156-707, Republic of Korea \\ ${ }^{3}$ Department of Laboratory Medicine, Boramae Hospital, Seoul 156-707, Republic of Korea \\ ${ }^{4}$ Seoul Metropolitan Government Public Cord Blood Bank (Allcord), Boramae Hospital, Seoul 156-707, Republic of Korea \\ ${ }^{5}$ Department of Obstetrics and Gynecology, Boramae Hospital, Seoul 156-707, Republic of Korea \\ ${ }^{6}$ Department of Paediatrics, Boramae Hospital, Seoul 156-707, Republic of Korea
}

Correspondence should be addressed to Sue Shin; jeannie@snu.ac.kr

Received 6 November 2012; Revised 11 March 2013; Accepted 11 March 2013

Academic Editor: Andrew St. John

Copyright ( $\odot 2013$ Hye Ryun Lee et al. This is an open access article distributed under the Creative Commons Attribution License, which permits unrestricted use, distribution, and reproduction in any medium, provided the original work is properly cited.

We evaluated the relationship between mean platelet volume (MPV) and characteristics of 10,577 cord blood (CB) units in a public $\mathrm{CB}$ bank in Korea. Blood group O has the highest MPV $(P=0.002)$. MPV correlated with CB volume $(r=0.121), \mathrm{Hb}(r=0.377)$, WBC $(r=0.111)$, TNCs $(r=0.110)$, CD34+ cell $(r=0.174)$, CD34+ cells/TNCs $(r=0.157)$, gestational age $(r=-0.102)$, and birth weight $(r=0.023)$; $(P<0.001$ in all). MPV may be one of the useful decision parameters of process priority in CB bank.

\section{Introduction}

Among CB units with similar TNC counts and HLA types, the CD34+ cell count is used to select the best unit [1-3]. To improve the quality of CB units in banks, robust and easy-toperform tests are needed to predict hematopoietic potency and transplantation outcomes before processing and storing $\mathrm{CB}$.

Mean platelet volume (MPV) has been reported to correlate with TNC and CD34+ cell counts, suggesting that MPV may be useful as a predictor of hematopoietic potency and transplantation outcomes [4]. Therefore, we retrospectively analyzed a large number of $\mathrm{CB}$ units to ascertain the relationship between MPV and hematopoietic parameters and other variables, including TNC and CD34+ cell counts, hemoglobin and platelet concentrations, WBC count, and maternal and neonatal factors. These values were also evaluated according to the $\mathrm{ABO}$ blood groups of the neonates.

\section{Design and Methods}

2.1. Subjects and Data Collection. Data from a total of $10,577 \mathrm{CB}$ units that were processed and stored at the Seoul Metropolitan Public Cord Blood Bank (Allcord) from October 2006 through August 2009 were analyzed. The CB units were donated by pregnant Korean women who provided informed consent. The study protocol was approved by the Institutional Review Board of Seoul National University Boramae Hospital (06-2012-64). We used in utero technique from the term healthy infant without any perinatal problems. CB was collected into a collection bag containing $24.5 \mathrm{~mL}$ citrate phosphate dextrose adenine-1 as an anticoagulant. Within 24 hours after delivery, the collected CB was transferred to the $\mathrm{CB}$ bank in a shipping container at $15^{\circ} \mathrm{C}$ to $25^{\circ} \mathrm{C}$ to maintain cell viability according to the standard operating procedures of Allcord. The units containing more than $60 \mathrm{~mL}$ CB (excluding anticoagulant) were subject to be processed. 
TABLE 1: Characteristics of mothers and neonates.

\begin{tabular}{|c|c|c|c|c|c|}
\hline Variable & $n$ & $\%$ & Mean \pm SD & Median & Range \\
\hline $\begin{array}{l}\text { Maternal age } \\
\text { (years old) }\end{array}$ & 10,577 & & $30.8 \pm 3.5$ & 31.0 & $16-49$ \\
\hline$<20$ & 20 & 0.2 & & & \\
\hline $20-24$ & 265 & 2.5 & & & \\
\hline $25-29$ & 3,561 & 33.7 & & & \\
\hline $30-34$ & 5,257 & 49.7 & & & \\
\hline $35-39$ & 1,363 & 12.9 & & & \\
\hline$\geq 40$ & 111 & 1.0 & & & \\
\hline $\begin{array}{l}\text { Gestational age } \\
\text { (weeks) }\end{array}$ & 10,577 & & $39.1 \pm 1.2$ & 39 & $32-42$ \\
\hline$<36$ & 57 & 0.5 & & & \\
\hline 36 & 165 & 1.6 & & & \\
\hline 37 & 669 & 6.3 & & & \\
\hline 38 & 2,136 & 20.2 & & & \\
\hline 39 & 3,157 & 29.8 & & & \\
\hline 40 & 3,361 & 31.8 & & & \\
\hline 41 & 1,014 & 9.6 & & & \\
\hline 42 & 18 & 0.2 & & & \\
\hline Birth weight (kg) & 10,577 & & $3.36 \pm 0.38$ & 3.35 & $1.66-6.70$ \\
\hline$\leq 2.50$ & 118 & 1.1 & & & \\
\hline $2.51-3.00$ & 1,693 & 16.0 & & & \\
\hline $3.01-3.50$ & 5,349 & 50.6 & & & \\
\hline $3.51-4.00$ & 2,956 & 27.9 & & & \\
\hline$>4.00$ & 461 & 4.4 & & & \\
\hline Sex of neonates & 10,577 & & & & \\
\hline Male & 5,456 & 51.6 & & & \\
\hline Female & 5,121 & 48.4 & & & \\
\hline Mode of delivery & 10,571 & & & & \\
\hline $\mathrm{V} / \mathrm{D}$ & 7,781 & 73.6 & & & \\
\hline $\mathrm{C} / \mathrm{S}$ & 2,790 & 26.4 & & & \\
\hline $\begin{array}{l}\text { ABO blood group } \\
\text { of neonates }\end{array}$ & 10,577 & & & & \\
\hline A & 3,669 & 34.7 & & & \\
\hline $\mathrm{B}$ & 2,854 & 27.0 & & & \\
\hline $\mathrm{O}$ & 2,844 & 26.9 & & & \\
\hline $\mathrm{AB}$ & 1,210 & 11.4 & & & \\
\hline
\end{tabular}

V/D: vaginal delivery; C/S: Cesarean section; SD: standard deviation.

The automated blood cell counter (XE-2100; Sysmex, Kobe, Japan) was used to determine the MPV and concentrations of $\mathrm{Hb}, \mathrm{WBCs}$, and platelets of all CB units. MPV was calculated by dividing the plateletcrit by the number of platelets. After volume reduction for cryopreservation, the blood was further tested to determine TNC and CD34+ cell counts and ABO blood group, according to the standard operating procedures of Allcord as described elsewhere [5].

Relationships between variables were determined by simple linear regression analysis. These variables were also compared according to $\mathrm{ABO}$ blood group by analysis of variance and the Kruskal-Wallis test. All statistical analyses
TABLE 2: Characteristics of 10,577 cord blood units.

\begin{tabular}{lccc}
\hline Variable & Mean \pm SD & Median & Range \\
\hline Volume $(\mathrm{mL})$ & $86.0 \pm 18.0$ & 83.0 & $53.9-201.2$ \\
$\mathrm{Hb}(\mathrm{g} / \mathrm{dL})$ & $11.7 \pm 1.3$ & 11.7 & $5.4-17.4$ \\
$\mathrm{WBCs}\left(\times 10^{3} / \mu \mathrm{L}\right)$ & $10.9 \pm 3.0$ & 10.4 & $3.2-31.2$ \\
Platelets $(/ \mu \mathrm{L})$ & $207 \pm 39$ & 205 & $72-422$ \\
$\mathrm{MPV}(\mathrm{fL})$ & $9.5 \pm 0.6$ & 9.4 & $7.6-13.2$ \\
$\mathrm{TNCs}\left(\times 10^{8} / \mathrm{unit}\right)$ & $8.8 \pm 3.0$ & 8.3 & $1.5-32.2$ \\
$\mathrm{CD} 34+$ cells $\left(\times 10^{6} /\right.$ unit $)$ & $1.15 \pm 1.09$ & 0.84 & $0.02-15.67$ \\
$\mathrm{CD} 34+$ cells/TNCs $(\%)$ & $0.123 \pm 0.089$ & 0.101 & $0.007-1.102$
\end{tabular}

$\mathrm{Hb}$ : hemoglobin; WBCs: white blood cells; MPV: mean platelet volume; TNCs: total nucleated cells; SD: standard deviation.

were performed using the Statistical Package for Society Sciences (SPSS) (version 12.0; IBM Corp., Chicago, IL, USA); $P<0.05$ was considered significant.

\section{Results and Discussion}

Table 1 shows the characteristics of the mothers (age) and neonates (gestational age, birth weight, sex, mode of delivery, and $\mathrm{ABO}$ blood group). Table 2 shows the following characteristics of the 10,577 CB units: volume, concentrations of $\mathrm{Hb}, \mathrm{WBCs}$, and platelets MPV from the units before volume reduction process and TNC count, CD34+ cell count, and CD34+ cells/TNCs from the units after the process. Analysis of the 10,577 CB units showed that MPV was positively correlated with $\mathrm{CB}$ volume $(r=0.121, P<0.001)$, $\mathrm{Hb}$ concentration $(r=0.377, P<0.001)$, and WBC count $(r=0.111$, $P<0.001)$ but not platelet concentration. In addition, MPV was positively correlated with TNC count $(r=0.110, P<$ $0.001)$, CD34+ cell count $(r=0.174, P<0.001)$, and CD34+ cells/TNCs $(r=0.157, P<0.001)$. No relationship was found between MPV and maternal age $(r=0.003, P=0.739)$. However, MPV was negatively correlated with gestational age $(r=-0.102, P<0.001)$ and positively correlated with birth weight $(r=0.023, P=0.020)$. Neonatal gender was not associated with MPV. When we did the multivariate analyses of MPV with CB volume, CD34+ cell count, WBC count, TNC, gestational age, and birth weight, the associations were also significant (see Supplementary Table 1 available online at: http://dx.doi.org/10.1155/2013/754169).

Table 3 shows the characteristics according to the $\mathrm{ABO}$ blood group. The birth weight of the neonates and $\mathrm{CB}$ values for $\mathrm{Hb}$ concentration, platelet concentration, and MPV differed according to $\mathrm{ABO}$ blood group. Although neonates with blood type $\mathrm{O}$ had the lowest birth weight $(P$ for trend $=0.003$ ), their $\mathrm{CB}$ units showed the highest MPV ( $P$ for trend $=0.002)$ and $\mathrm{Hb}$ concentration $(P$ for trend $<0.001)$. In contrast, $\mathrm{CB}$ units from neonates with blood type $\mathrm{A}$ had the highest platelet concentration $(P$ for trend $<0.001)$.

The present study shows that the MPV of $\mathrm{CB}$ correlates with TNC and CD34+ cell counts and the ratio of CD34+ cells to TNCs in the processed CB units, which is consistent with the results of previous studies $[4,6]$. Our study is significant 
TABLE 3: Gestational age, birth weight, cord blood volume, blood cell components, mean platelet volume, and other hematopoietic parameters of the cord blood units according to $\mathrm{ABO}$ blood group of neonates.

\begin{tabular}{|c|c|c|c|c|c|}
\hline & $\begin{array}{c}\mathrm{A} \\
(n=3669)\end{array}$ & $\begin{array}{c}\mathrm{B} \\
(n=2854)\end{array}$ & $\begin{array}{c}\mathrm{O} \\
(n=2844)\end{array}$ & $\begin{array}{c}\mathrm{AB} \\
(n=1210)\end{array}$ & $P$ \\
\hline Gestational age (weeks) & $39.1 \pm 1.2$ & $39.1 \pm 1.2$ & $39.1 \pm 1.2$ & $39.1 \pm 1.2$ & 0.406 \\
\hline Birth weight (kg) & $3.37 \pm 0.38$ & $3.35 \pm 0.38$ & $3.34 \pm 0.37$ & $3.37 \pm 0.37$ & 0.003 \\
\hline Volume (mL) & $86.3 \pm 18.2$ & $85.6 \pm 17.8$ & $86.1 \pm 18.2$ & $86.0 \pm 18.0$ & 0.393 \\
\hline $\mathrm{Hb}(\mathrm{g} / \mathrm{dL})$ & $11.6 \pm 1.3$ & $11.7 \pm 1.3$ & $11.8 \pm 1.3$ & $11.6 \pm 1.3$ & $<0.001$ \\
\hline WBCs $\left(\times 10^{3} / \mu \mathrm{L}\right)$ & $10.8 \pm 3.1$ & $10.9 \pm 2.9$ & $11.0 \pm 3.1$ & $10.8 \pm 3.1$ & 0.092 \\
\hline Platelets $(/ \mu \mathrm{L})$ & $209 \pm 39$ & $205 \pm 38$ & $206 \pm 39$ & $206 \pm 38$ & $<0.001$ \\
\hline MPV (fL) & $9.486 \pm 0.607$ & $9.446 \pm 0.610$ & $9.507 \pm 0.617$ & $9.466 \pm 0.616$ & 0.002 \\
\hline
\end{tabular}

SD: standard deviation; Hb: hemoglobin; MPV: mean platelet volume; WBCs: white blood cells; TNCs: total nucleated cells.

because of the large number of $\mathrm{CB}$ units analyzed from a Korean CB bank.

We previously reported the relationship between $\mathrm{ABO}$ blood group and hematopoietic parameters (TNC count, CD34+ cell count, and CD34+ cells/TNCs) in CB units [5]. $\mathrm{CB}$ obtained from neonates with blood type $\mathrm{O}$ has higher TNC and CD34+ cell counts and ratio of CD34+ cells to TNCs than neonates with other blood types; therefore, CB units with blood type $\mathrm{O}$ may have greater hematopoietic potency. In this study, we also found that neonates with blood type $\mathrm{O}$ had significantly higher MPV. However, neonates with blood type $\mathrm{A}$, not neonates of blood type $\mathrm{O}$, had the highest platelet concentration.

In this study, we found that MPV appeared to be inversely correlated with platelet concentration in CB units, but this relationship was not statistically significant. Studies have reported a nonlinear inverse relationship between MPV and platelet count in the peripheral blood of adults $[7,8]$. In contrast, a positive correlation has been reported between MPV and platelet concentration in CB units; however, that study analyzed only 167 units [4]. We analyzed a pretty much larger number of CB units in our study $(10,577)$; therefore, we believe there is no proof of relationship between MPV and platelet concentration. Our finding that MPV positively correlated with $\mathrm{Hb}$ is consistent with that of a previous study [6]. MPV was also positively correlated with WBC concentration.

MPV was not associated with maternal age or neonatal gender but was negatively correlated with gestational age and positively correlated with birth weight.

Anticoagulants can affect MPV in CB after collection. In particular, EDTA causes time-dependent platelet swelling, which increases MPV [9]. Therefore, it is important to use alternative anticoagulants and reduce the time between collection and analysis. Because MPV changes can be reduced using citrate-based anticoagulants $[10,11]$, we used collection bags containing the citrate-based anticoagulant CPDA-1. In addition, platelet clumping and early clotting is a concern after ex utero collection of CB. Therefore, we collected CB in utero to better evaluate the relationship between platelet concentration and MPV.

In summary, this study reveals that the MPV of $\mathrm{CB}$ units correlates with TNC and CD34+ cell counts and the gestational age and birth weight of neonates. MPV is routinely measured with other blood components using automatic hematologic analyzer before $\mathrm{CB}$ processing but is not currently used as a predictor of hematopoietic potency. However, MPV values combined with CB volume limit of $60 \mathrm{~mL}$ before processing and TNC and CD34+ cell counts after processing may be useful in the selection of high-quality units for storage.

\section{Authors' Contribution}

SS was the principal investigator and takes primary responsibility for the paper. B. J. Kim and J. Y. Chang recruited the cord blood and data. E. Y. Roh, J. H. Yoon, and E. Y. Song coordinated the research. H. R. Lee and J. S. Park wrote the paper and did the statistical analysis.

\section{Conflict of Interests}

The authors reported no potential conflict of interests.

\section{Acknowledgments}

The authors would like to thank all the staffs of the Allcord for their technical assistance and greatly appreciate the consideration of Korean mothers who voluntarily donate cord blood to the public cord blood bank. This work was supported by the Clinical Research Fund from SMG-SNU Boramae Hospital (03-2008-05).

\section{References}

[1] A. R. Migliaccio, J. W. Adamson, C. E. Stevens, N. L. Dobrila, C. M. Carrier, and P. Rubinstein, "Cell dose and speed of engraftment in placental/umbilical cord blood transplantation: graft progenitor cell content is a better predictor than nucleated cell quantity," Blood, vol. 96, no. 8, pp. 2717-2722, 2000.

[2] N. Schmitz and J. Barrett, "Optimizing engraftment-source and dose of stem cells," Seminars in Hematology, vol. 39, no. 1, pp. 3-14, 2002.

[3] J. E. Wagner, J. N. Barker, T. E. DeFor et al., "Transplantation of unrelated donor umbilical cord blood in 102 patients with malignant and nonmalignant diseases: influence of CD34 cell dose and HLA disparity on treatment-related mortality and survival," Blood, vol. 100, no. 5, pp. 1611-1618, 2002. 
[4] M. Eskola, S. Rekunen, P. Aroviita et al., "Association of cord blood platelet characteristics and hematopoietic progenitor cells," Transfusion, vol. 48, no. 5, pp. 884-892, 2008.

[5] H. R. Lee, J. S. Park, S. Shin et al., "Increased numbers of total nucleated and CD34+ cells in blood group O cord blood: an analysis of neonatal innate factors in the Korean population," Transfusion, vol. 52, no. 1, pp. 76-81, 2012.

[6] M. Eskola, S. Juutistenaho, K. Aranko, S. Sainio, and R. Kekomäki, "Association of cord blood platelet count and volume with hemoglobin in healthy term infants," Journal of Perinatology, vol. 31, no. 4, pp. 258-262, 2011.

[7] B. J. Bain, "Platelet count and platelet size in males and females," Scandinavian Journal of Haematology, vol. 35, no. 1, pp. 77-79, 1985.

[8] J. D. Bessman, “The relation of megakaryocyte ploidy to platelet volume," American Journal of Hematology, vol. 16, no. 2, pp. 161170, 1984.

[9] K. M. Bowles, L. J. Cooke, E. M. Richards, and T. P. Baglin, "Platelet size has diagnostic predictive value in patients with thrombocytopenia," Clinical and Laboratory Haematology, vol. 27, no. 6, pp. 370-373, 2005.

[10] M. S. Dastjerdi, T. Emami, A. Najafian, and M. Amini, "Mean platelet volume measurement, EDTA or citrate?" Hematology, vol. 11, no. 5-6, pp. 317-319, 2006.

[11] C. B. Thompson, D. D. Diaz, P. G. Quinn, M. Lapins, S. R. Kurtz, and C. R. Valeri, "The role of anticoagulation in the measurement of platelet volumes," American Journal of Clinical Pathology, vol. 80, no. 3, pp. 327-332, 1983. 

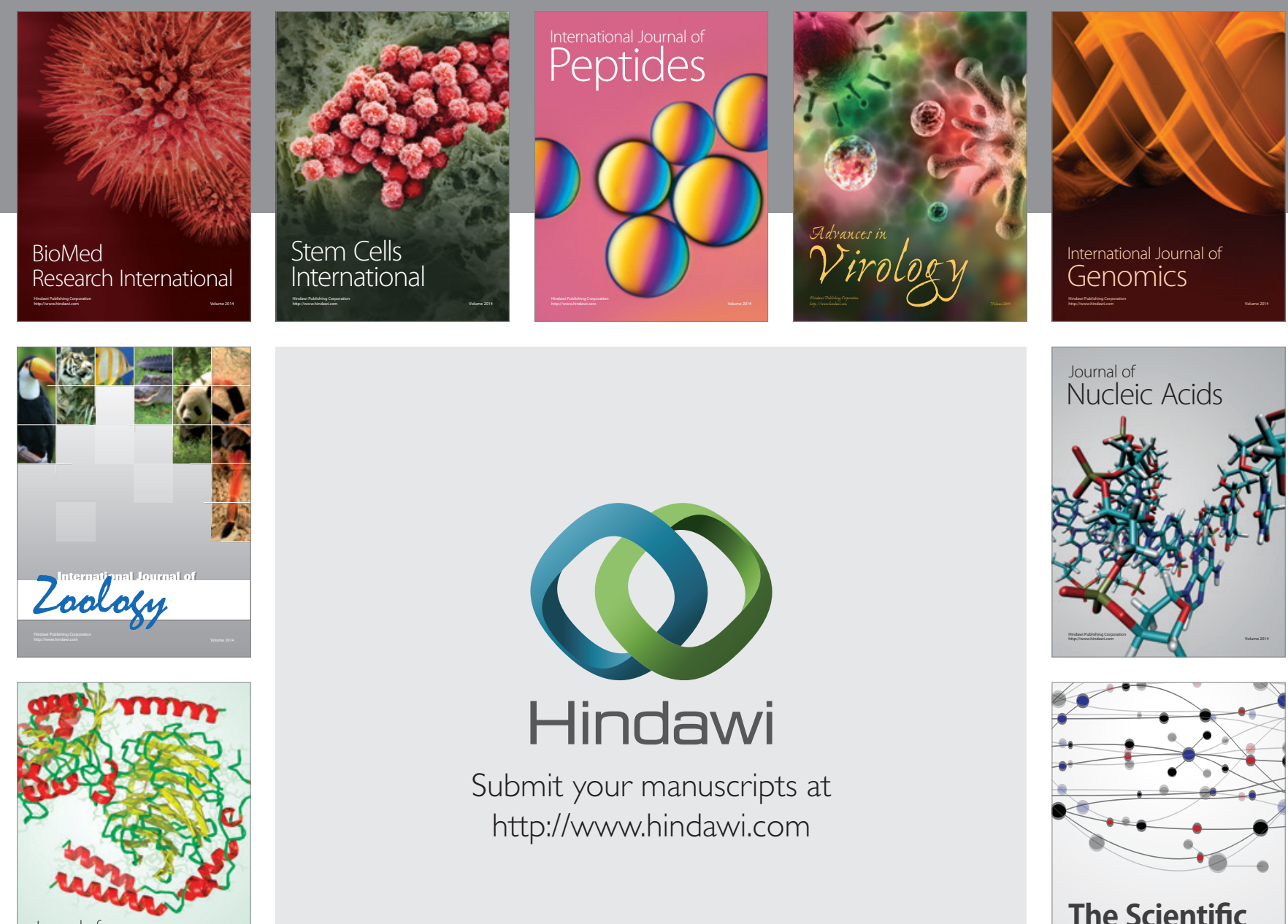

Submit your manuscripts at

http://www.hindawi.com

Journal of
Signal Transduction
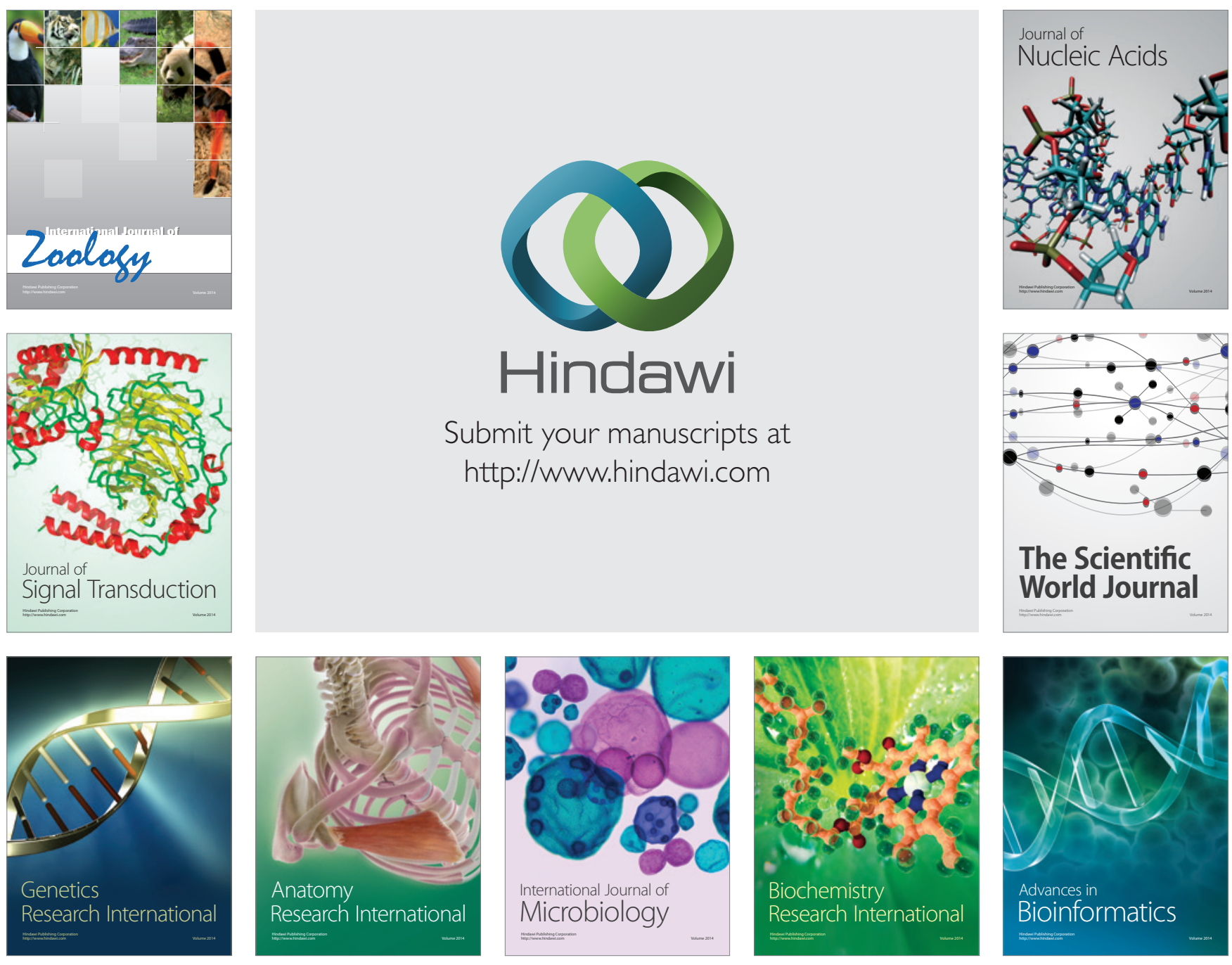

The Scientific World Journal
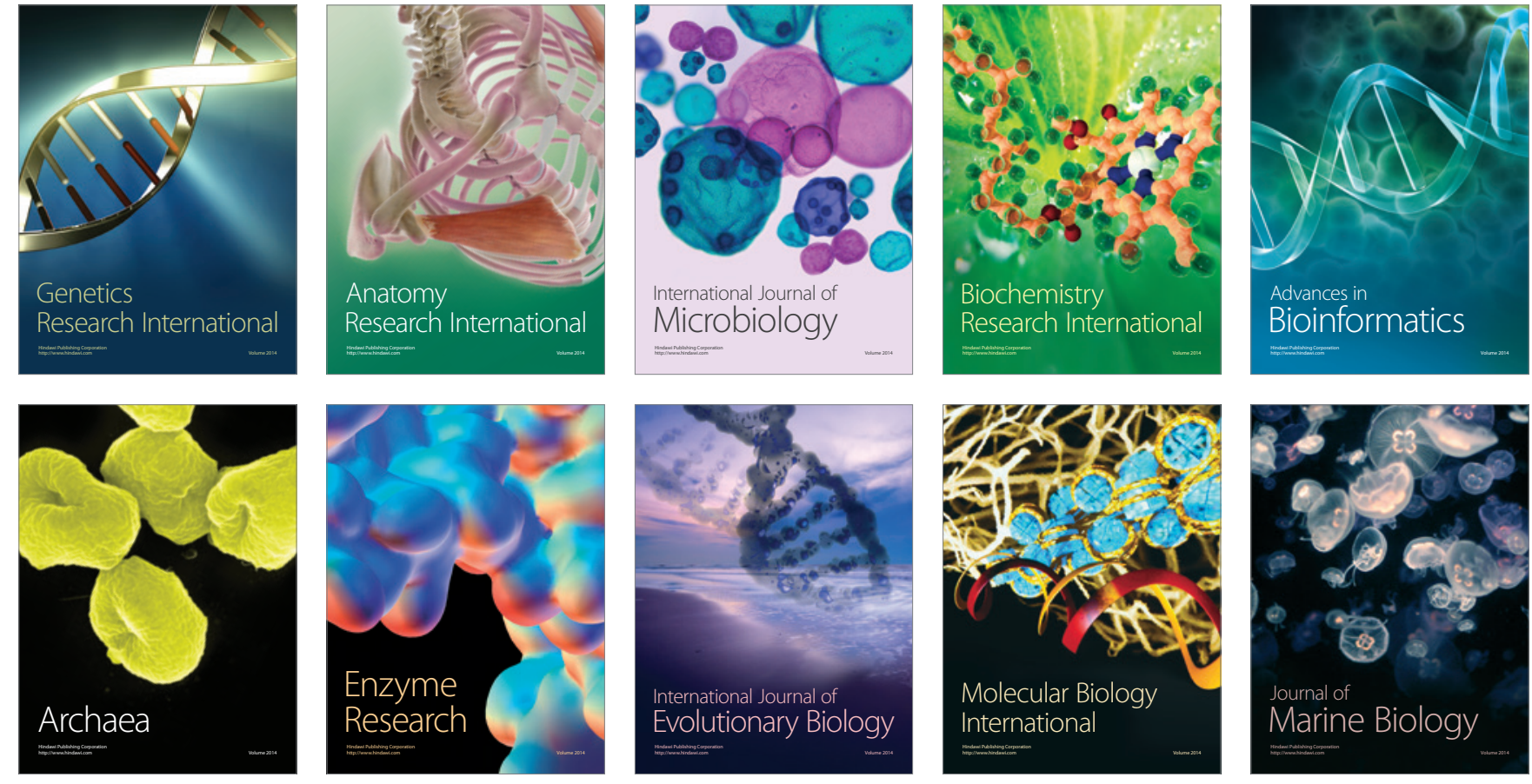